Article

\title{
An Active-Clamp Forward Inverter Featuring Soft Switching and Electrical Isolation
}

\author{
Chien-Hsuan Chang $* \mathbb{}$, Chun-An Cheng $\odot$, Hung-Liang Cheng $®$ and Yen-Ting Wu \\ Department of Electrical Engineering, I-Shou University, Dashu District, Kaohsiung City 84001, Taiwan; \\ cacheng@isu.edu.tw (C.-A.C.); hlcheng@isu.edu.tw (H.-L.C.); e12345678902001@gmail.com (Y.-T.W.) \\ * Correspondence: chchang@isu.edu.tw; Tel.: +886-7-657-7711 (ext. 6641)
}

Received: 24 May 2020; Accepted: 18 June 2020; Published: 19 June 2020

\begin{abstract}
Traditional photovoltaic (PV) grid-connection inverters with sinusoidal pulse-width modulation (SPWM) control suffer the problem of buck-typed conversion. Additional line-frequency transformers or boost converters are required to step-up output voltage, leading to low system efficiency and high circuit complexity. Therefore, many flyback inverters with electrical isolation have been proposed by adopting a flyback converter to generate a rectified sine wave, and then connecting with a bridge unfolder to control polarity. However, all energy of a flyback inverter must be temporarily stored in the magnetizing inductor of transformer so that the efficiency and the out power are limited. This paper presents a high-efficiency active-clamp forward inverter with the features of zero-voltage switching (ZVS) and electrical isolation. The proposed inverter circuit is formed by adopting a forward converter to generate a rectified sine wave, and combining with the active-clamp circuit to reset the residual magnetic flux of the transformer. Due to the boost capability of the transformer, this inverter is suitable for the PV grid-connection power systems with wide input-voltage variation. The operation principles at steady-state are analyzed, and the mathematical equations for circuit design are conducted. Finally, a laboratory prototype is built as an illustration example according to proper analysis and design. Based on the experimental results, the feasibility and satisfactory performance of the proposed inverter circuit are verified.
\end{abstract}

Keywords: photovoltaic (PV); inverter; active-clamp; zero voltage switching (ZVS); grid-connection

\section{Introduction}

Today, because photovoltaic (PV) energy is noiseless, pollution-free, non-radioactive and inexhaustible, PV grid-connection power systems are receiving increasing attention [1-3]. For the PV grid-connected systems, inverters are necessary to convert the DC voltage of the PV panel to an AC voltage, and then supply power in parallel with utility-line. Therefore, many experts have invested in the research of the circuit architecture and control strategy of inverters [4-7]. The full-bridge voltage-source inverter is the popular topology in low-power PV grid-connected systems. However, due to its buck-typed conversion, a line-frequency transformer has to be inserted between the inverter and utility-line. This system structure greatly increases the volume, weight and cost of the system, and reduces the power density.

Inserting a boost converter to step-up the output voltage of the PV panel is the alternative solution. The boost converter can not only regulate PV output voltage but also achieve maximum power point tracking (MPPT) [8,9]. The main advantage of this two-stage cascade structure is the independent control of the power converters. It is easy to optimize the function of each stage, and the input voltage of the inverter is regulated. However, the disadvantages are the increase in the complexity of the system circuit, the increase in cost, and the reduction in reliability. The power loss due to multiple energy processing will reduce the overall system efficiency. The pseudo-dc-link inverters are 
proposed to improve these shortcomings [10,11]. In these inverters, a DC converter is used to generate a single-polarity rectified sine wave, and a line-frequency bridge unfolding circuit is used to switch the polarity of the output voltage. Since there is only single energy processing, power loss can be reduced to improve efficiency.

Among these high-efficiency inverters with pseudo-dc-link, the buck-boost type converters are widely used to implement non-isolated inverters for the photovoltaic grid-connected power system with wide-range input voltage fluctuation [12-15]. Furthermore, in order to obtain higher boosting capacity and meet the safety requirement of electrical isolation, isolated DC-DC converters, such as flyback converter, are often used to design isolated pseudo-dc-link inverters [16-19]. The flyback converter has the advantages of simple structure and easy control. However, because the transformer of the flyback converter needs to function as an inductor for energy storage, all energy needs to be temporarily stored in the transformer and then transferred to the output load, so its output power and efficiency are limited.

In order to improve the output power and conversion efficiency of the inverter with electrical isolation, the forward inverter is proposed [20], where the forward converter is adopted to replace the flyback converter and to generate a rectified sine wave. However, since the forward converter needs a third winding of the transformer to reset its residual magnetic flux, the maximum duty ratio of the power switch is limited, thereby reducing the boosting capacity of the converter. The dual-switch forward inverter [21] adds additional power switches, diodes, and a secondary winding to reset the residual magnetic flux of the transformer. The transformer can be operated in both of the first and third quadrants, but its volume and total circuit cost are greatly increased. Therefore, an active-clamp forward inverter is proposed in this paper. By replacing the traditional reset winding with an auxiliary switch and a clamp capacitor, the residual magnetic flux can be reset through the resonance of the clamp capacitor and the magnetizing inductor. In addition to recovering the energy of the magnetizing inductor back to the input, the power switch can also be turned on with zero voltage switching (ZVS) to reduce switching losses and effectively increase the efficiency of the inverter. Circuit configuration, operation principles, and design considerations will be presented sequentially in the following. Finally, a laboratory prototype of the proposed inverter is built accordingly to verify the feasibility of the proposed circuit architecture and the correctness of the theoretical analysis.

\section{Circuit Configuration}

As mentioned previously, the popular PV grid-connection systems need a line-frequency transformer or a boost converter to step-up output voltage. Their system block diagrams are shown in Figures 1 and 2, respectively. In order to improve efficiency and reduce cost, the pseudo-dc-link inverters are proposed, as shown in Figure 3. However, these inverters are non-isolated, which may not avoid the leakage current of the PV panel. Therefore, an active-clamp forward inverter featuring soft switching and electrical isolation is proposed in this paper.

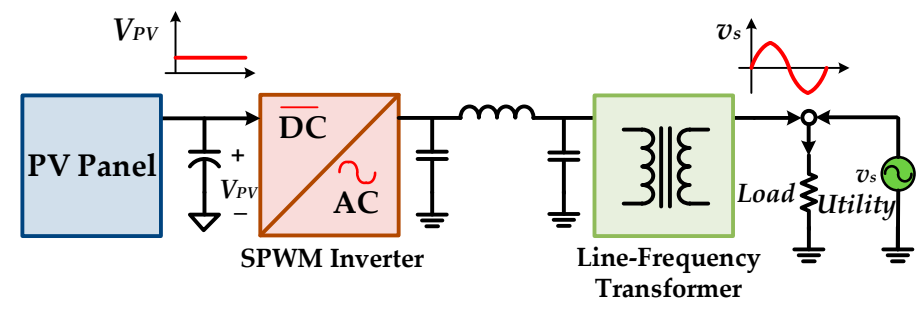

Figure 1. PV grid-connection systems with a line-frequency transformer. 


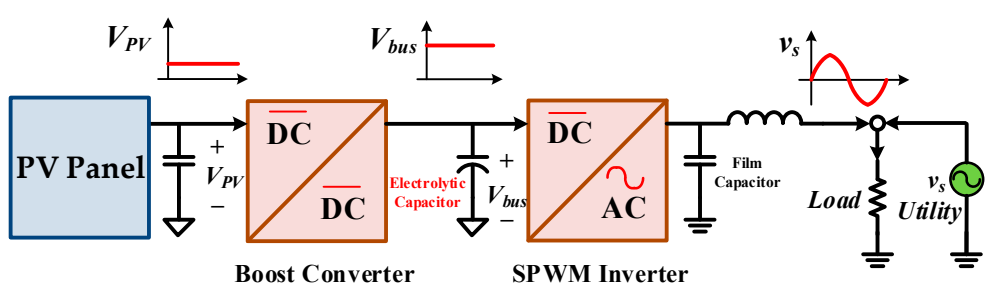

Figure 2. PV grid-connection systems with the two-stage cascade structure.

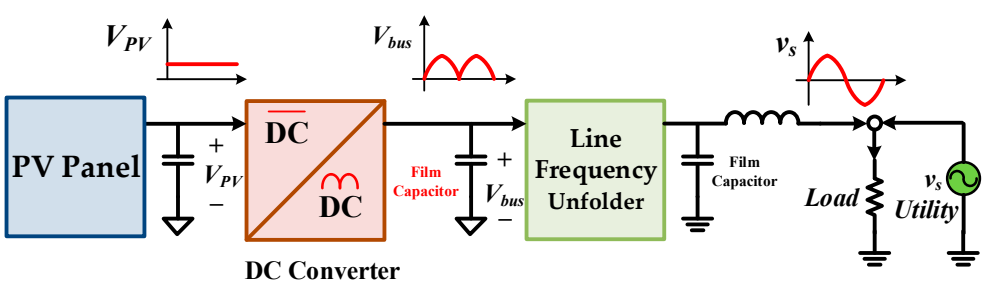

Figure 3. PV grid-connection systems with the pseudo-dc-link structure.

The circuit diagram of the proposed inverter is shown in Figure 4. The active-clamp forward converter with zero voltage switching is used to generate the single-polarity rectified sine wave, and the full-bridge unfolding circuit with line-frequency switching switches the output polarity. The power stage of the active-clamp forward converter mainly consists of the main power switch $S_{m 1}$ (including MOSFET $Q_{m 1}$, body diode $D_{m 1}$, and parasitic capacitor $C_{d s 1}$ ), the real transformer $T_{x 1}$ (including magnetizing inductor $L_{m 1}$ and ideal transformer with turn ratio 1:n), the forward diode $D_{1}$, the freewheel diode $D_{2}$, the inductor $L_{1}$, and the output capacitor $C_{\mathrm{f}}$. The auxiliary switch $S_{a 1}$ (including MOSFET $Q_{a 1}$ and body diode $D_{a 1}$ ) and the clamp capacitor $C_{c 1}$ are used for resetting the residual magnetic flux of the transformer. The energy of the magnetizing inductor $L_{m 1}$ and the clamp capacitor $C_{c 1}$ are alternately transferred. Except for effectively recovering the energy of residual magnetic to the input power source, both the switches $S_{m 1}$ and $S_{a 1}$ can achieve ZVS characteristics to reduce switching losses. In addition, the full-bridge unfolding circuit consists of the power switches $S_{1}, S_{2}, S_{3}$ and $S_{4}$, and the output filter is formed of the inductor $L_{0}$ and the capacitor $C_{0}$. The power switches $S_{1}$, $S_{2}, S_{3}$ and $S_{4}$ are only switching with line frequency, so that there is almost no switching loss.

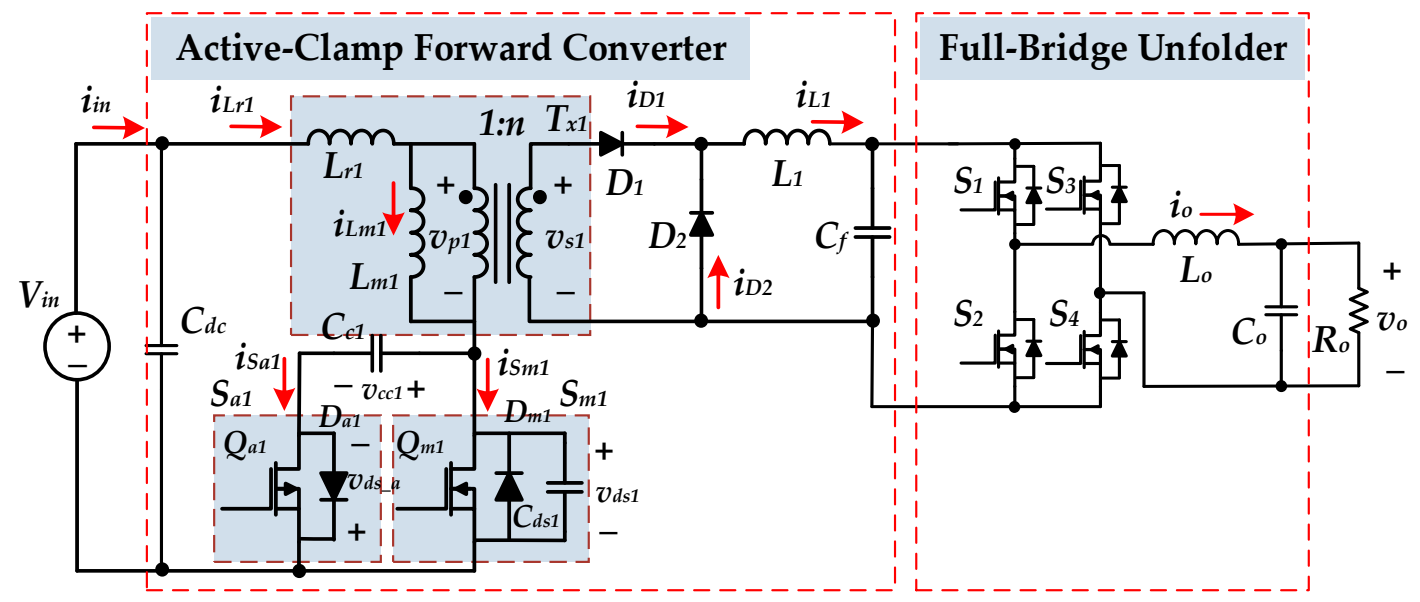

Figure 4. The circuit configuration of the proposed active-clamp forward inverter.

The traditional voltage source inverter is the buck type. In order to obtain a DC input voltage higher than the peak voltage of utility-line, an additional boost converter is necessarily adopted, resulting in low system conversion efficiency. Since the active-clamp forward inverter has both step-up and step-down functions, the boost converter is no longer required. The proposed inverter is suitable for the application with low input voltage and wide voltage variation. In addition, because partial 
energy can be directly transmitted to the output during the main switch $S_{m 1}$ turning-on, the proposed inverter can effectively improve the conversion efficiency. Since only two switches $S_{m 1}$ and $S_{a 1}$ are switching with high frequency, the switching loss can be greatly reduced to improve system efficiency.

\section{Operation Principles}

The proposed active-clamp forward inverter is controlled by SPWM. When the inverter operates at steady state, the duty ratio of the main switch $S_{m 1}$ and the auxiliary switch $S_{a 1}$ can be respectively expressed as follows [22]:

$$
\begin{gathered}
d_{m 1}(t)=\frac{V_{M} \sin \omega t}{n V_{\text {in }}}, \\
d_{a 1}(t)=1-d_{m 1}(t)=1-\frac{V_{M} \sin \omega t}{n V_{\text {in }}} .
\end{gathered}
$$

The on-time of the main switch $S_{m 1}$ is $d_{m 1} T_{s}$, and the on-time of the auxiliary switch $S_{a 1}$ is $\left(1-d_{m 1}\right)$ $T_{S}$, where $T_{S}$ is the high-frequency switching period. Assuming that the inverter operates in continuous conduction mode (CCM), when the main switch $S_{m 1}$ is turned on and the auxiliary switch $S_{a 1}$ is turned off, the voltage $v_{p 1}$ across the transformer magnetizing inductance is equal to the input voltage $V_{\text {in }}$ and expressed as:

$$
v_{p 1}=V_{\text {in }}
$$

When the main switch $S_{m 1}$ is turned off and the auxiliary switch $S_{a 1}$ is turned on, the voltage $v_{p 1}$ across the transformer magnetizing inductance is changed to be:

$$
v_{p 1}=V_{\text {in }}-v_{c c 1}
$$

where $v_{c c 1}$ is the voltage across the clamp capacitor $C_{c 1}$. According to the volt-second balance theorem, the relationship between the input voltage $V_{i n}$ and $v_{c c 1}$ can be expressed as follows:

$$
V_{i n} d_{m 1} T_{s}=\left(v_{c c 1}-V_{i n}\right)\left(1-d_{m 1}\right) T_{s} .
$$

Arranging Equation (5) can get the relationship between $v_{c c 1}$ and $V_{\text {in }}$ as:

$$
v_{c c 1}=\frac{1}{\left(1-d_{m 1}\right)} V_{i n} .
$$

It can be found from Equation (6) that the transfer function of the voltage $v_{c c 1}$ is the same as that of the boost converter. When the main switch $S_{m 1}$ is turned off, since the auxiliary switch $S_{a 1}$ is turned on, the voltage $v_{d s 1}$ across the main switch $S_{m 1}$ is:

$$
v_{d s 1}=v_{c c 1}=\frac{1}{\left(1-d_{m 1}\right)} V_{i n} .
$$

According to the state of the switching components and the direction of their currents, the operation of the active-clamp forward inverter can be divided into nine states in one high-frequency switching period. The theoretical timing diagram of each component is shown in Figure 5, and the nine states will be described in order in the following. To simplify the circuit analysis, the following assumptions are made:

1. All components are ideal.

2. The clamp capacitor $C_{c 1}$ is much larger than the parasitic capacitor $C_{d s 1}$ of the main power switch, and the magnetizing inductor $L_{m 1}$ of the transformer is much larger than the leakage inductor $L_{r 1}$.

3. The inductor $L_{1}$ and the capacitor $C_{f}$ are large enough so that the output voltage $v_{\mathrm{O}}$ and the output current $i_{\mathrm{o}}$ can be regarded as constant in one switching period.

4. Because the dead time is extremely short, it can be ignored. 


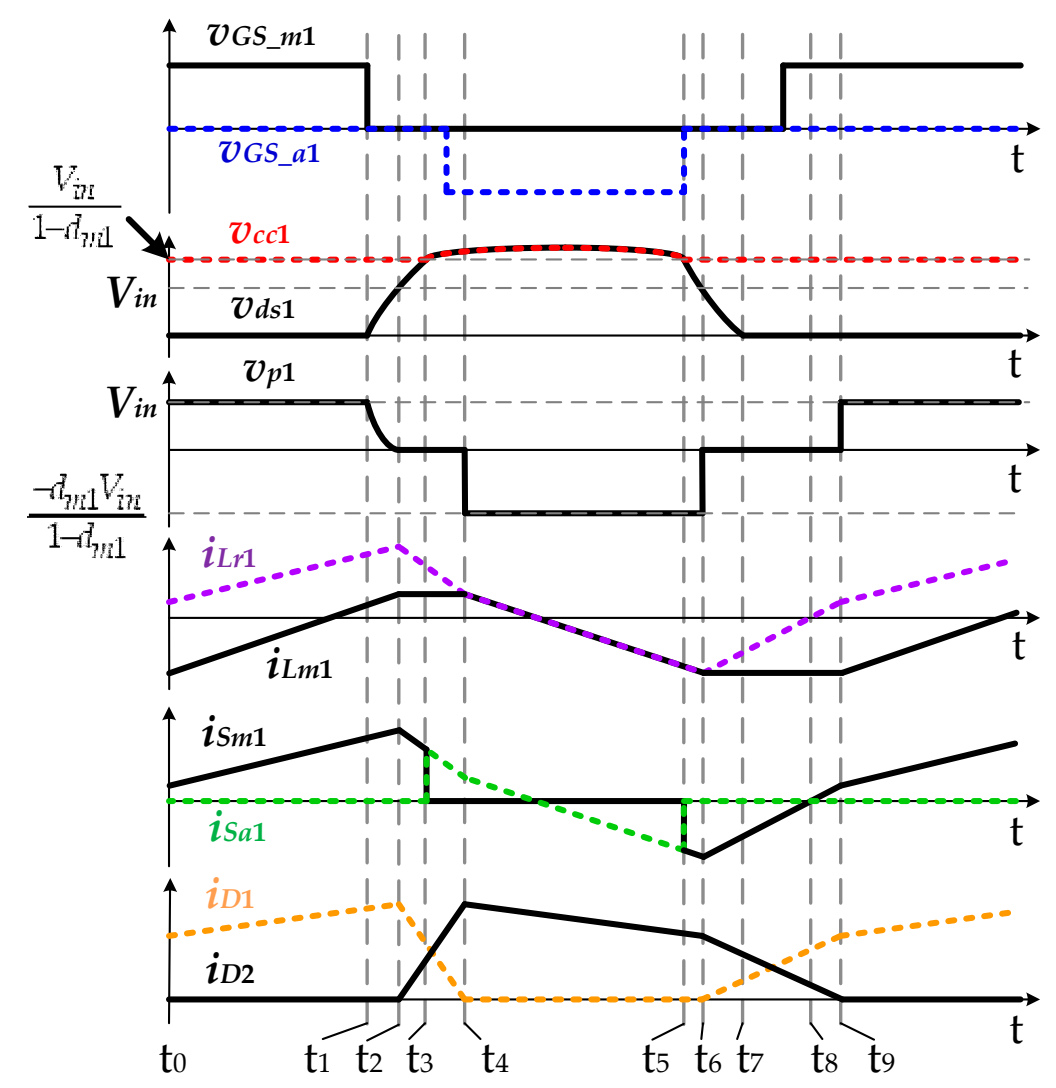

Figure 5. The theoretical timing diagram of key components in one switching period.

\section{A. State $1\left(t_{0}<t<t_{1}\right.$, Figure $\left.6 a\right)$}

At the time $t=t_{0}$, the main power switch $S_{m 1}$ is turned on, and the auxiliary switch $S_{a 1}$ is turned off. At this time, the primary voltage $v_{p 1}$ across the transformer magnetizing inductor is equal to $V_{i n}$, so the current $i_{L m 1}$ through magnetizing inductor rises linearly. The secondary voltage $v_{s 1}$ of transformer is $V_{i n} / n$, so the forward diode $D_{1}$ is forward biased, and the freewheel diode $D_{2}$ is reverse biased. The input power is transmitted to the inductor $L_{1}$ and the load $R_{\mathrm{o}}$ via the transformer $T_{x 1}$ and the diode $D_{1}$. The equivalent circuit is as shown in Figure 6a. The voltage $v_{d s 1}$ across the main switch $S_{m 1}$ and the current $i_{L r 1}$ through the leakage inductor can be expressed as

$$
\begin{gathered}
v_{d s 1}(t)=0 \\
i_{L r 1}(t)=i_{L m 1}(t)+\frac{i_{D 1}(t)}{n}=i_{L m 1}(t)+\frac{I_{L o}}{n},
\end{gathered}
$$

where $I_{L o}$ is the average current of the output inductor $L_{\mathrm{o}}$ in one switching period. At the time $t=t_{1}$, the main switch $S_{m 1}$ is switched off, and the circuit operation enters the next state.

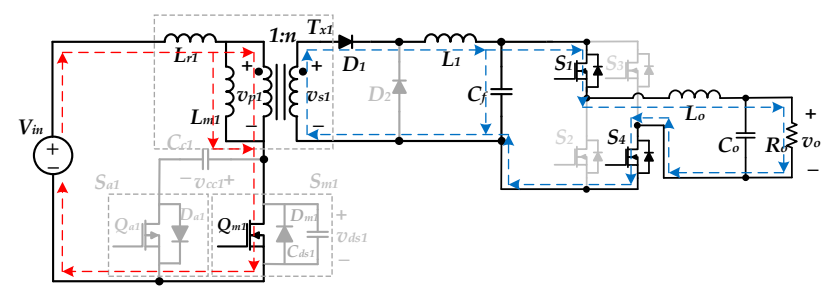

(a)

Figure 6. Cont. 


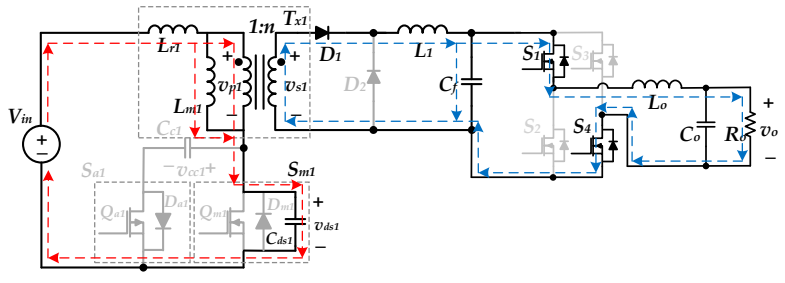

(b)

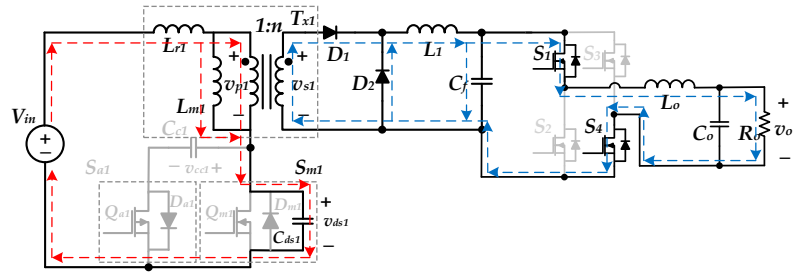

(c)

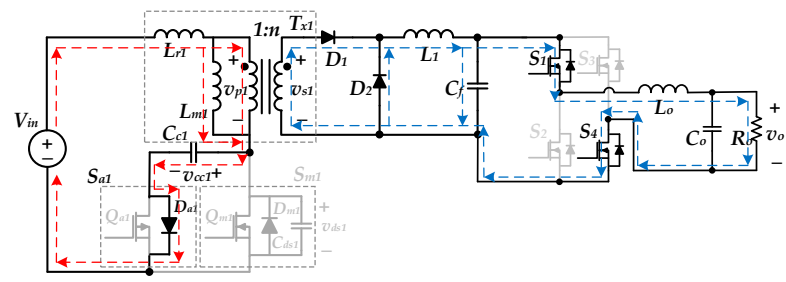

(d)

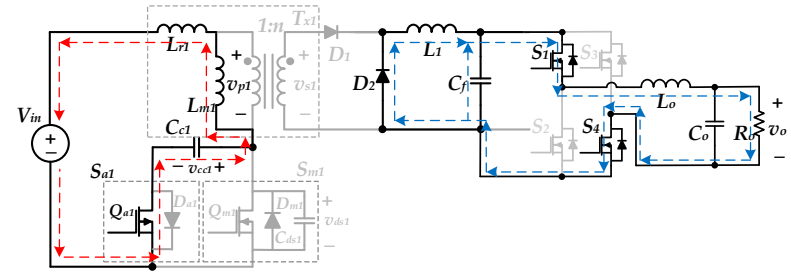

(e)

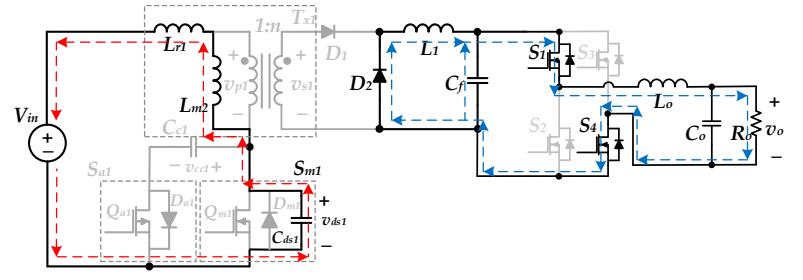

(f)

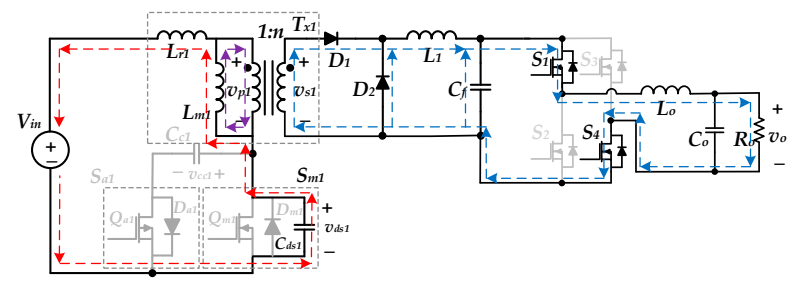

(g)

Figure 6. Cont. 


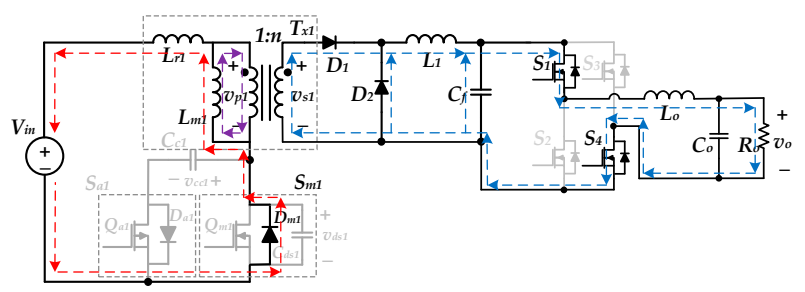

(h)

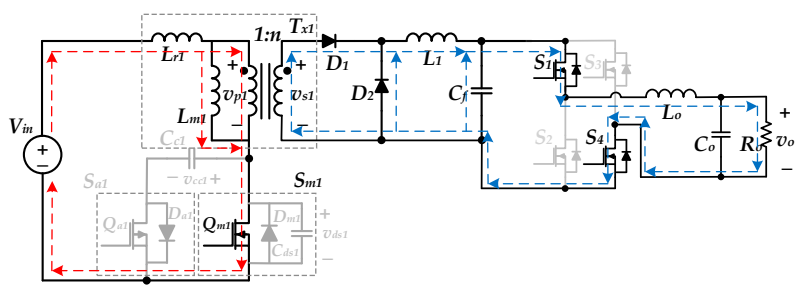

(i)

Figure 6. The equivalent circuits of each operating state during the positive half line-cycle. (a) State 1 $\left[t_{0}<t<t_{1}\right]$, (b) state $2\left[t_{1}<t<t_{2}\right]$, (c) state $3\left[t_{2}<t<t_{3}\right]$, (d) state $4\left[t_{3}<t<t_{4}\right]$, (e) state $5\left[t_{4}<t<t_{5}\right]$, (f) state $6\left[t_{5}<t<t_{6}\right],(\mathrm{g})$ state $7\left[t_{6}<t<t_{7}\right]$, (h) state $8\left[t_{7}<t<t_{8}\right]$, (i) state $9\left[t_{8}<t<t_{9}\right]$.

B. State $2\left(t_{1}<t<t_{2}\right.$, Figure $\left.6 b\right)$

When the main switch $S_{m 1}$ is switched off, the leakage inductor $L_{r 1}$, the magnetizing inductor $L_{m 1}$, and the parasitic capacitance $C_{d s 1}$ are resonant in series. The current $i_{L r 1}$ of leakage inductor starts to charge the capacitor $C_{d s 1}$, the voltage $v_{d s 1}$ starts to rise, and the primary voltage $v_{p 1}$ starts to drop. At this time, the forward diode $D_{1}$ remains on, and the freewheel diode $D_{2}$ remains off. The equivalent circuit of this state is as shown in Figure $6 \mathrm{~b}$. The voltage $v_{d s 1}$ across the main switch and the current $i_{L r 1}$ through the leakage inductor can be expressed as

$$
\begin{gathered}
v_{d s 1}(t)=V_{i n}\left[1-\cos \omega_{1}\left(t-t_{1}\right)\right]+i_{L r 1}(t) Z_{1} \sin \omega_{1}\left(t-t_{1}\right), \\
i_{L r 1}(t)=i_{L r 1}\left(t_{1}\right) \cos \omega_{1}\left(t-t_{1}\right)+\frac{V_{\text {in }}}{Z_{1}} \sin \omega_{1}\left(t-t_{1}\right),
\end{gathered}
$$

where $\omega_{1}=\frac{1}{\sqrt{C_{d s 1}\left(L_{r 1}+L_{m 1}\right)}}$, and $Z_{1}=\sqrt{\frac{\left(L_{r 1}+L_{m 1}\right)}{C_{d s 1}}}$. The time the state 2 required can be expressed as follows:

$$
t_{2}-t_{1}=\frac{1}{\omega_{1}} \tan ^{-1}\left[\frac{V_{\text {in }}}{i_{\text {Lr1 }}\left(t_{1}\right) Z_{1}}\right] .
$$

At the time $t=t_{2}, v_{d s 1}$ rises to be equal to $V_{i n}$, this state ends and goes to the next state.

\section{State $3\left(t_{2}<t<t_{3}\right.$, Figure $\left.6 c\right)$}

At the time $t=t_{2}$, the primary voltage $v_{p 1}$ drops to be zero, so that both the forward diode $D_{1}$ and the freewheel diode $D_{2}$ are turned on. The forward diode current $i_{D 1}$ is gradually reduced, and the freewheel diode current $i_{D 2}$ is gradually increased. The equivalent circuit is shown in Figure $6 \mathrm{c}$. When the voltage $v_{d s}$ increases, the leakage inductor current $i_{L r 1}$ decreases and can be expressed as:

$$
i_{L r 1}(t)=\frac{i_{D 1}(t)}{n}+i_{L m 1}(t) .
$$


The magnetizing current $i_{L m 1}$ remains unchanged. At this time, the voltage $v_{d s 1}$ and the leakage inductor current $i_{L r 1}$ can be respectively expressed as:

$$
\begin{gathered}
v_{d s 1}(t)=V_{i n}+i_{L r 1}\left(t_{2}\right) Z_{2} \sin \omega_{2}\left(t-t_{2}\right), \\
i_{L r 1}(t)=i_{L r 1}\left(t_{2}\right) \cos \omega_{2}\left(t-t_{2}\right),
\end{gathered}
$$

where $\omega_{2}=\frac{1}{\sqrt{L_{r 1} C_{d s 1}}}$, and $Z_{2}=\sqrt{\frac{L_{r 1}}{C_{d s 1}}}$. When the voltage $v_{d s 1}$ arrives $V_{i n} /\left(1-d_{m 1}\right)$, the leakage inductor current $i_{L r 1}$ stops charging the capacitor $C_{d s 1}$, and the circuit operation enters the next state.

\section{State $4\left(t_{3}<t<t_{4}\right.$, Figure $\left.6 d\right)$}

At the time $t=t_{3}$, the leakage inductor current $i_{L r 1}$ is charging the clamp capacitor $C_{C 1}$ via the anti-parallel diode $D_{a 1}$ of the auxiliary switch $S_{a 1}$, so the voltage across $S_{a 1}$ is zero. The equivalent circuit is shown in Figure 6d. Since the anti-parallel diode $D_{a 1}$ is turned on, the gate driving signal of the auxiliary switch $S_{a 1}$ must be provided during this state to achieve ZVS. At this time, the primary voltage $v_{p 1}$ is zero. The clamp-capacitor voltage $v_{c c 1}$ and the leakage inductor current $i_{L r 1}$ can be expressed as

$$
\begin{gathered}
v_{c c 1}(t)=V_{\text {in }}-\left[V_{\text {in }}-v_{c c 1}\left(t_{3}\right)\right] \cos \omega_{3}\left(t-t_{3}\right)+i_{L r 1}\left(t_{3}\right) Z_{3} \sin \omega_{3}\left(t-t_{3}\right), \\
i_{L r 1}(t)=i_{L r 1}\left(t_{3}\right) \cos \omega_{3}\left(t-t_{3}\right)+\frac{V_{i n}-v_{c c 1}\left(t_{3}\right)}{Z_{3}} \sin \omega_{3}\left(t-t_{3}\right),
\end{gathered}
$$

where $\omega_{3}=\frac{1}{\sqrt{L_{r 1} C_{c 1}}}$, and $Z_{3}=\sqrt{\frac{L_{r 1}}{C_{c 1}}}$. When $i_{L r 1}$ is equal to $i_{L m 1}$, the forward diode current $i_{D 1}$ drops to zero, and this state ends.

\section{E. State $5\left(t_{4}<t<t_{5}\right.$, Figure $\left.6 e\right)$}

At the time $t=t_{4}$, since the forward diode current $i_{D 1}$ is zero, the magnetizing inductor $L_{m 1}$ is in series with the leakage inductor $L_{r 1}$, and resonates with the clamping capacitor $C_{c 1}$. The primary voltage $v_{p 1}$ is $-d_{m 1} V_{i n} /\left(1-d_{m 1}\right)$, and the equivalent circuit is as shown in Figure 6e. The leakage inductor current $i_{L r 1}$ is equal to the magnetizing inductor current $i_{L m 1}$ and continues decreasing. Due to the resonance, the direction of the current $i_{L m 1}$ is reversed during this state, forcing the stored energy of the magnetizing inductor $L_{m 1}$ to be recycled to the input power source. In this state, the clamp-capacitor voltage $v_{c c 1}$ and the leakage inductor current $i_{L r 1}$ can be expressed as

$$
\begin{gathered}
v_{c c 1}(t)=V_{\text {in }}-\left[V_{\text {in }}-v_{c c 1}\left(t_{4}\right)\right] \cos \omega_{4}\left(t-t_{4}\right)+i_{L r 1}\left(t_{4}\right) Z_{4} \sin \omega_{4}\left(t-t_{4}\right), \\
i_{L r 1}(t)=i_{L r 1}\left(t_{4}\right) \cos \omega_{4}\left(t-t_{4}\right)+\frac{V_{i n}-v_{c c 1}\left(t_{4}\right)}{Z_{4}} \sin \omega_{4}\left(t-t_{4}\right),
\end{gathered}
$$

where $\omega_{4}=\frac{1}{\sqrt{\left(L_{r 1}+L_{m 1}\right) C_{c 1}}}$, and $Z_{4}=\sqrt{\frac{\left(L_{r 1}+L_{m 1}\right)}{C_{c 1}}}$. This state ends when the driving signal of the auxiliary switch $S_{a 1}$ disappears.

\section{F. State $6\left(t_{5}<t<t_{6}\right.$, Figure $\left.6 f\right)$}

At the time $t=t_{5}$, the auxiliary switch $S_{a 1}$ is turned off. The primary voltage $v_{p 1}$ is $-d_{m 1} V_{i n} /\left(1-d_{m 1}\right)$, so that the secondary voltage $v_{s 1}$ is also negative. At this time, the resonant current flows through the capacitor $C_{d s 1}$ to force it discharging, and the voltage $v_{d s 1}$ decreases. The equivalent circuit is as shown in Figure $6 f$. In this state, the voltage $v_{d s} 1$ and the leakage inductor current $i_{L r 1}$ can be expressed as:

$$
v_{d s 1}(t)=V_{i n}-\left[V_{i n}-v_{c c 1}\left(t_{5}\right)\right] \cos \omega_{1}\left(t-t_{5}\right)+i_{L r 1}\left(t_{5}\right) Z_{1} \sin \omega_{1}\left(t-t_{5}\right),
$$




$$
i_{L r 1}(t)=i_{L r 1}\left(t_{5}\right) \cos \omega_{1}\left(t-t_{5}\right)+\frac{V_{i n}-v_{c c 1}\left(t_{5}\right)}{Z_{1}} \sin \omega_{1}\left(t-t_{5}\right)
$$

where $\omega_{1}=\frac{1}{\sqrt{C_{d s 1}\left(L_{r 1}+L_{m 1}\right)}}$, and $Z_{1}=\sqrt{\frac{\left(L_{r 1}+L_{m 1}\right)}{C_{d s}}}$. This state ends when the voltage $v_{d s 1}$ drops to $V_{i n}$, and the time it takes is as follows:

$$
t_{6}-t_{5}=\frac{1}{\omega_{1}} \tan ^{-1}\left[\frac{V_{i n}-v_{c 1}\left(t_{5}\right)}{Z_{1} i_{L r 1}\left(t_{5}\right)}\right] .
$$

\section{G. State $7\left(t_{6}<t<t_{7}\right.$, Figure $\left.6 g\right)$}

At the time $t=t_{6}$, the voltage $v_{d s 1}$ drops to $V_{i n}$, causing the primary voltage $v_{p 1}$ equal to zero again. The magnetizing inductor $L_{m 1}$ no longer participates in resonance, and its current remains constant. The voltage across the leakage inductor $L_{r 1}$ is $V_{i n}$, so its current $i_{L r 1}$ rises linearly from a negative value and with the slope of $V_{i n} / L_{r 1}$. In addition, the forward diode $D_{1}$ is turned on again, so that the current $i_{D 1}$ increases, and the freewheel diode current $i_{D 2}$ decreases. The equivalent circuit is as shown in Figure $6 \mathrm{~g}$. The voltage $v_{d s 1}$ across the main switch and the leakage inductor current $i_{L r 1}$ are expressed as:

$$
\begin{gathered}
v_{d s 1}(t)=V_{i n}+i_{L r 1}\left(t_{6}\right) Z_{2} \sin \omega_{2}\left(t-t_{6}\right) \\
i_{L r 1}(t)=i_{L r 1}\left(t_{6}\right) \cos \omega_{2}\left(t-t_{6}\right)
\end{gathered}
$$

where $\omega_{2}=\frac{1}{\sqrt{L_{r 1} C_{d s 1}}}$, and $Z_{2}=\sqrt{\frac{L_{r 1}}{C_{d s 1}}}$. Since the direction of the current $i_{L r 1}$ cannot be changed instantaneously, the anti-parallel diode $D_{m 1}$ is forced to turn on, and the energy is recovered to the input. In order for the main switch $S_{m 1}$ to have the ZVS characteristic, Equation (23) should satisfy $v_{d s 1}(t) \leq 0$ before this state ends. The following conditions can be obtained:

$$
\left|i_{L r 1}\left(t_{6}\right) Z_{2}\right| \geq V_{\text {in }}
$$

When the voltage $v_{d s 1}$ continues dropping to zero, this state ends and the time it takes is:

$$
t_{7}-t_{6}=\frac{1}{\omega_{2}} \sin ^{-1}\left[-\frac{V_{i n}}{i_{L r 1}\left(t_{6}\right) Z_{2}}\right]
$$

\section{H. State $8\left(t_{7}<t<t_{8}\right.$, Figure $\left.6 h\right)$}

At the time $t=t_{7}$, the current $i_{L r 1}$ flows through the anti-parallel diode $D_{m 1}$ to release the energy stored in the magnetizing inductance $L_{m 1}$ back to the input power source, and the equivalent circuit is as shown in Figure 6h. The driving signal of the main power switch $S_{m 1}$ should be applied in this interval. Since the anti-parallel diode $D_{m 1}$ has been turned on, the switch $S_{m 1}$ can achieve the characteristic of ZVS turn-on. Because the forward diode $D_{1}$ and the freewheel diode $D_{2}$ are remained being on state, the leakage inductor current $i_{L r 1}$ continues to increase linearly with the slope of $V_{i n} / L_{r 1}$, and can be expressed as:

$$
i_{L r 1}(t)=i_{L r 1}\left(t_{7}\right)+\frac{V_{i n}}{L_{r 1}}\left(t-t_{7}\right) .
$$

When the current $i_{L r 1}$ rises to be zero, this mode ends and the time it takes is:

$$
t_{8}-t_{7}=\frac{-L_{r} i_{L_{r}}\left(t_{7}\right)}{V_{\text {in }}} .
$$

I. $\quad$ State $9\left(t_{8}<t<t_{9}\right.$, Figure $\left.6 i\right)$ 
At the time $t=t_{8}$, the leakage inductor current $i_{L r 1}$ becomes positive. The forward diode current $i_{D 1}$ continues to increase linearly, and the freewheel diode current $i_{D 2}$ continues to decrease linearly. The equivalent circuit is shown in Figure $6 \mathrm{i}$. In this state, the voltage $v_{d s} 1$ across the main switch and the leakage inductance current $i_{L r 1}$ can be respectively expressed as:

$$
\begin{gathered}
v_{d s 1}(t)=0, \\
i_{L r 1}(t)=i_{L r 1}\left(t_{8}\right)+\frac{V_{\text {in }}}{L_{r 1}}\left(t-t_{8}\right) .
\end{gathered}
$$

When the diode $D_{2}$ is turned off at the time $t=t_{9}$, the state ends, and one switching period of the proposed inverter is completed. The circuit operation will return to the state 1 of the next switching period, and the nine operation states are repeated in sequence. The time it takes for this stage is:

$$
t_{9}-t_{8}=\frac{L_{r 1}}{V_{i n}}\left(\frac{I_{L o}}{n}+i_{L m 1}\left(t_{0}\right)-i_{L r 1}\left(t_{8}\right)\right) .
$$

It can be seen from the above analyses that the advantages of the proposed inverter are listed as follows:

1. The magnetizing inductor current $i_{L m 1}$ of the transformer is bidirectional, so the iron core is operated in the first and third quadrants of the hysteresis curve, which can improve the core utilization.

2. Replacing the traditional reset winding, the auxiliary switch $S_{a 1}$ and the clamp capacitor $C_{C 1}$ are used to reset the residual magnetic flux of the transformer. The energies of the magnetizing inductor and the clamp capacitor are mutually transferred so that the energy can be recycled to the input. Since both the magnetizing inductor and the clamping capacitor are passive components for energy storage, there is theoretically no power loss.

3. By using the magnetizing inductor and the leakage inductor of the transformer, both the main power switch $S_{m 1}$ and the auxiliary switch $S_{a 1}$ achieve the characteristics of ZVS turn-on, which can effectively reduce the switching loss.

\section{Grid-Connection System and Control Circuit}

The circuit diagram of a PV grid-connection power system using the proposed active clamp forward inverter is shown in Figure 7, which mainly includes a PV array, a dc-link capacitor $C_{d c}$, and an active clamp forward inverter, system controller, load and utility-line. The core of the system controller is the digital signal processor (DSP) dsPIC33FJ16GS504. Except for extremely fast operations, this DSP has built-in analog/digital conversion (ADC) and multiple pulse-width-modulation (PWM) control signals. Due to the Harvard structure, it can analyze load current components, and sample voltage and current signals, simultaneously. Digital design can simplify hardware circuits and reduce the number of components, resulting in small size, light weight, high flexibility and high reliability.

The main function of the PV grid-connected power system is to deliver solar energy to utility-line. Since the maximum PV power changes with sunlight intensity and temperature, the inverter output current should regulate accordingly. The control circuit diagram of the PV grid-connection power system is shown in Figure 8. By inputting the feedback voltage $V_{P V, f}$ and the feedback current $I_{P V, f}$ from the PV panel to the MPPT controller, the level of the output current command $i_{\mathrm{o}}{ }^{*}$ is changed accordingly. The MPPT controller uses the perturbation \& observation $(\mathrm{P} \& \mathrm{O})$ algorithm $[8,9]$ and is implemented by the DSP, which can ensure that the system can draw the maximum power from the PV panel and feed it into the utility-line. The current command $i_{\mathrm{o}}{ }^{*}$ is a half-wave, and its frequency is twice the frequency of the line voltage $\mathrm{v}_{\mathbf{s}}$. By comparing the output current feedback signal $i_{\mathrm{o}, f}$ with the output current command $i_{\mathrm{o}}{ }^{*}$, the obtained error signal $i_{\text {err }}$ will adjust the SPWM switch driving signal through the compensator $G_{c c}$. Therefore, the output current $i_{\mathrm{o}}$ can have the same frequency and the same phase as the line voltage $v_{s}$, and the solar energy can be completely fed into the utility-line 
or the load. In addition, a square wave signal $v_{P}$ with the same frequency as line voltage $v_{S}$ can be obtained by the phase detector, which can be used to generate the driving signal of the low-frequency bridge unfolding circuit.

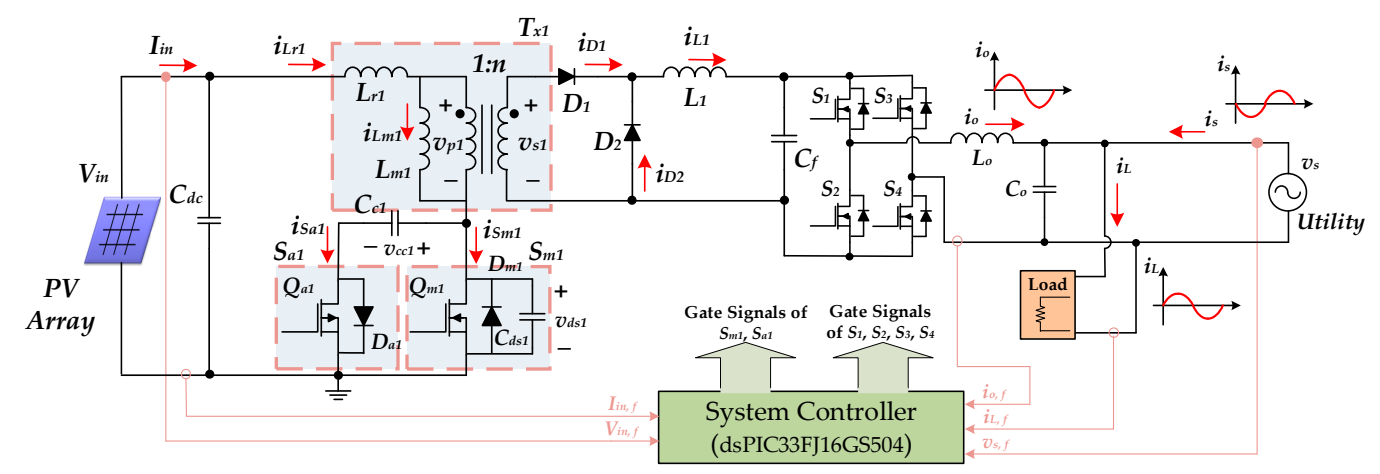

Figure 7. The circuit diagram of a grid-connection power system using the proposed active-clamp forward inverter.

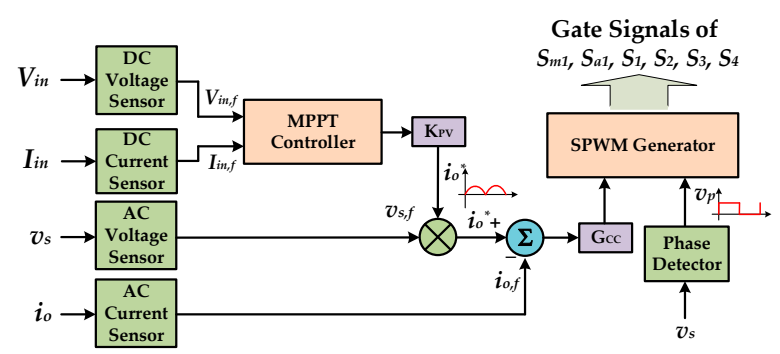

Figure 8. The block diagram of the control circuit of the PV grid-connection power system.

\section{Experimental Results}

According to the foregoing analysis, a DSP-based prototype of the proposed inverter is built as an example for illustration. Refer to the circuit diagram shown in Figure 7, the electrical specifications are listed in Table 1.

Table 1. Electrical specifications of the proposed inverter.

\begin{tabular}{cc}
\hline \multicolumn{2}{c}{ Electrical Specifications } \\
\hline Typical input voltage, $V_{\text {in }}$ & $48 \mathrm{~V}$ \\
Output voltage, $v_{\mathrm{o}}$ & $110 \mathrm{~V}_{\mathrm{rms}}$ \\
Line frequency, $f_{a c}$ & $60 \mathrm{~Hz}$ \\
Switching frequency, $f_{s}$ & $20 \mathrm{kHz}$ \\
Output power, $P_{\mathrm{o}}$ & $400 \mathrm{~W}$ \\
\hline
\end{tabular}

Considering that the input voltage is $48 \mathrm{~V}$ and the peak output voltage $V_{\mathrm{o}, p}$ is $156 \mathrm{~V}$, the transformer turns ratio $(n)$ is selected as 10 . From the transfer function of the forward converter, the duty ratio can be calculated as:

$$
d_{m 1}=\frac{V_{o, p}}{n \times V_{i n}}=0.325
$$

The boundary inductance $L_{B}$ of $L_{1}$ in boundary conduction mode (BCM) can be derived as:

$$
L_{B}=\frac{V_{o, p} \times\left(1-d_{m 1}\right)}{\mathrm{I}_{o} \times 2 f_{s}}
$$

The inductor current is selected to operate in BCM under 20\% load current and the peak of the output voltage. Therefore, the boundary inductance $L_{B}$ can be calculated from Equation (33) to be 
$2.57 \mathrm{mH}$. This boundary value is the minimum of output inductor $L_{1}$, so the inductance of $3 \mathrm{mH}$ is selected in the implementation example.

In this design, the magnetizing inductor $L_{m 1}$ of the transformer is $835 \mu \mathrm{H}$. From the operation principles mentioned before, the condition of that main switch $S_{m 1}$ achieves ZVS is:

$$
Z_{2} \geq \frac{V_{\text {in }}}{\left|i_{\text {Lr1 }}\left(t_{6}\right)\right|^{\prime}}
$$

where $Z_{2}=\sqrt{\frac{L_{r 1}}{C_{d s 1}}}$. From Equation (23), the current $i_{L r 1}\left(t_{6}\right)$ can be obtained as:

$$
i_{L r 1}\left(t_{6}\right)=\frac{d_{m 1} V_{i n}}{2 L_{m} f_{s}}
$$

By combining Equations (34) and (35), the minimum value of the leakage inductance $L_{r 1}$ can be calculated as follows:

$$
L_{r 1} \geq \frac{4 f_{s}^{2} \times C_{d s 1} \times L_{m 1}^{2}}{d_{m 1}^{2}}=3.38(\mu H) .
$$

Choose $4 \mu \mathrm{H}$ as the inductance of the leakage inductor $L_{r} 1$.

Besides, the active-clamp forward inverter uses the auxiliary switch $S_{a 1}$ and the clamp capacitor $C_{c 1}$ to reset the residual magnetizing flux of the transformer. When the resonance of $C_{c 1}, L_{r 1}$ and $L_{m 1}$ occurs, the small value of $C_{c 1}$ will shorten the resonant period and induce voltage spikes. As a result, the voltage stresses of the clamp capacitor $C_{c 1}$, the main switch $S_{m 1}$, and the auxiliary switch $S_{a 1}$ are increased. Therefore, the resonant period should be designed to be greater than ten times the main switch turn-off time, that is:

$$
2 \pi \times \sqrt{\left(L_{r 1}+L_{\mathrm{m} 1}\right) \times C_{c 1}} \geq 10 \times\left(1-d_{m 1}\right) T_{S} .
$$

From Equation (37), the capacitance of $C_{c 1}$ can be calculated as:

$$
C_{c 1} \geq \frac{100 \times\left(1-d_{m 1}\right)^{2}}{\left(L_{r 1}+L_{m 1}\right) \times\left(2 \pi f_{s}\right)^{2}}=3.44(\mu \mathrm{F}) .
$$

Choose $4 \mu \mathrm{F}$ as the capacitance of the clamp capacitor $C_{c 1}$.

According to the previous design and calculations, the selected component parameters are summarized in Table 2. The experimental results described below will be used to verify the feasibility of the proposed circuit architecture and the correctness of the theoretical analysis.

Table 2. Component parameters of the proposed inverter.

\begin{tabular}{cc}
\hline \multicolumn{2}{c}{ Component Parameters } \\
\hline Bus filter, $C_{d c}$ & $2000 \mu \mathrm{F}$ \\
Main switch, $S_{m 1} 1$ & $6 \mathrm{R} 045$ \\
Auxiliary switch, $S_{a 1}$ & $47 \mathrm{~N} 60 \mathrm{C} 3$ \\
MOSFETs, $S_{1}-S_{4}$ & $47 \mathrm{~N} 60 \mathrm{C} 3$ \\
Diodes, $D_{1}, D_{2}$ & $\mathrm{C} 3 \mathrm{D} 10060 \mathrm{~A}$ \\
Transformer turn ratio, $n$ & 10 \\
Magnetizing inductor, & $835 \mu \mathrm{H}$ \\
$L_{m} 1$ & $4 \mu \mathrm{H}$ \\
Leakage inductor, $L_{r 1}$ & $4 \mu \mathrm{F}$ \\
Clamping capacitor, $C_{c 1}$ & $3 \mathrm{mH}$ \\
Inductor, $L_{1}$ & $4.7 \mu \mathrm{F}$ \\
Capacitor, $C_{f}$ & $1 \mathrm{mH}$ \\
Output inductor, $L_{\mathrm{o}}$ & $4.7 \mu \mathrm{F}$ \\
Output capacitor, $C_{\mathrm{o}}$ &
\end{tabular}


The proposed active-clamp forward inverter is driven by SPWM signals. Figure $9 \mathrm{a}, \mathrm{b}$ are the simulation and measured waveforms of the output voltage $v_{\mathrm{o}}$ and output current $i_{\mathrm{o}}$ when the inverter is operated at $48 \mathrm{~V}$ input voltage, and Figure $9 \mathrm{c}, \mathrm{d}$ are the simulation and measured waveforms of the output voltage $v_{\mathrm{O}}$ and output inductor current $i_{L 1}$. It can be seen from the figures that the output voltage and current are in the form of a sine wave with low distortion, which proves that this isolated inverter can effectively convert the DC voltage into an AC output. Furthermore, Figure 10 shows the measured waveforms of the output voltage $v_{\mathrm{o}}$ and output current $i_{\mathrm{o}}$ when the inverter operates with the step load change between $320 \mathrm{~W}$ and $160 \mathrm{~W}$. As can be seen, the output voltage can be quickly and stably regulated to a sine wave of $110 \mathrm{~V}_{\mathrm{rms}}$, proving that the proposed inverter has good dynamic voltage regulation capability. In addition, the line regulation is $1.26 \%$, and the load regulation is $0.78 \%$, which meets the general specifications of $\pm 3 \%$.

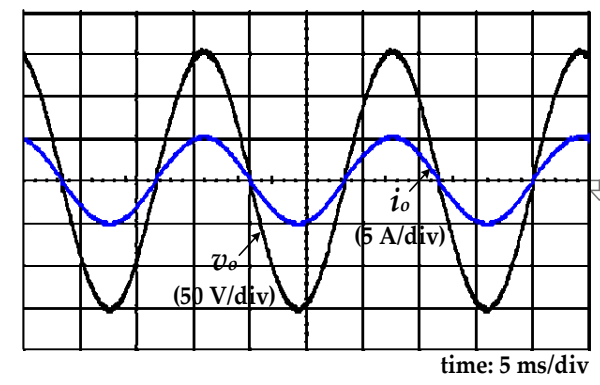

(a)

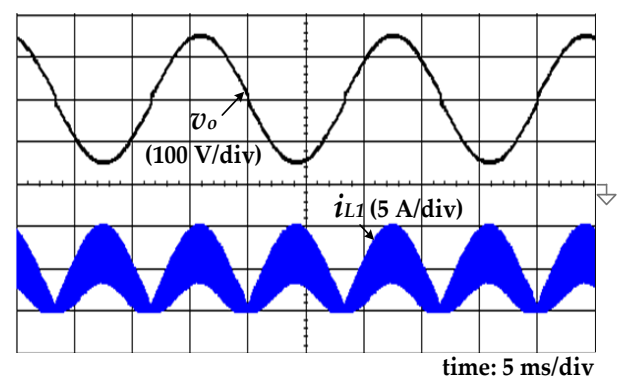

(c)

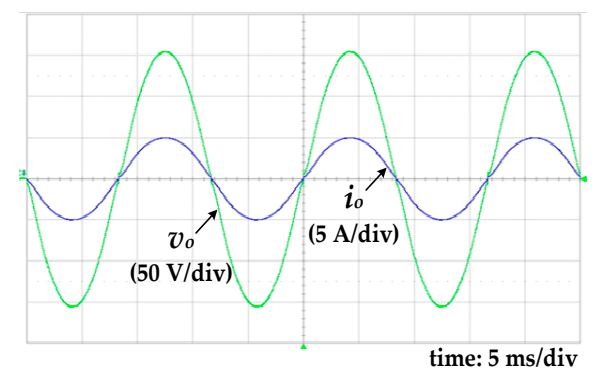

(b)

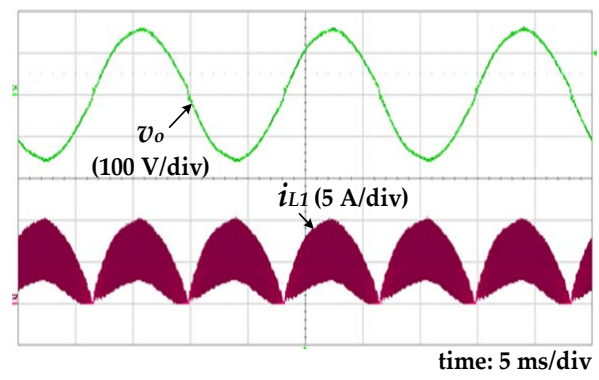

(d)

Figure 9. (a) Simulation waveforms of $v_{\mathrm{o}}$ and $i_{\mathrm{O}},(\mathbf{b})$ measured waveforms of $v_{\mathrm{o}}$ and $i_{\mathrm{o}}$, (c) simulation waveforms of $v_{\mathrm{O}}$ and $i_{L 1}$, and (d) measured waveforms of $v_{\mathrm{O}}$ and $i_{L 1}$, at $48 \mathrm{~V}$ input voltage and a full load of $400 \mathrm{~W}$.

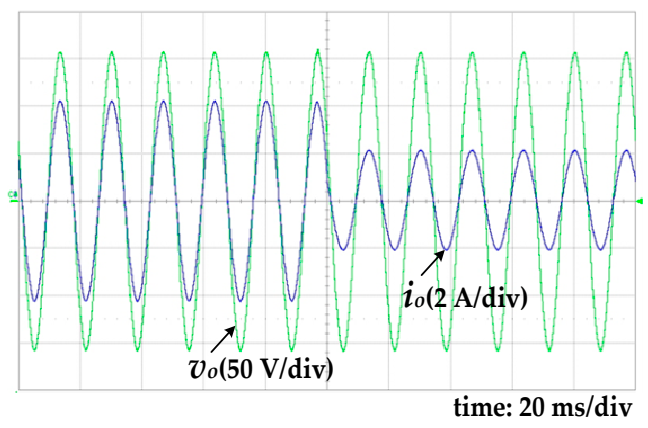

(a)

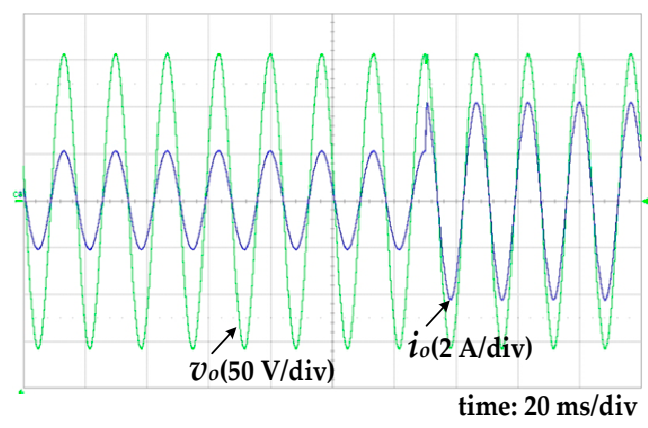

(b)

Figure 10. Measured waveforms of output voltage $v_{\mathrm{o}}$ and output current $i_{\mathrm{o}}$ when the inverter is operated with a step-load change of (a) from $320 \mathrm{~W}$ to $160 \mathrm{~W}$; (b) from $160 \mathrm{~W}$ to $320 \mathrm{~W}$.

Figure 11 shows the simulation and measured waveforms of the main-switch voltage $v_{d s} 1$, the main-switch current $i_{s m 1}$, and the clamp-capacitor voltage $v_{c c 1}$, when the inverter is operated at $48 \mathrm{~V}$ 
input voltage and the full load of $400 \mathrm{~W}$. Since the resonant current flows through the anti-parallel diode $D_{m 1}$ before the main switch $S_{m 1}$ is turned on, it can be seen from Figure 11a,b that the main switch $S_{m 1}$ can achieve the characteristics of ZVS turn-on, which can effectively reduce switching loss. In addition, it can be seen from Figure $11 \mathrm{c}, \mathrm{d}$ that the maximum value of the clamp-capacitor voltage $v_{c c 1}$ is about $95 \mathrm{~V}$, which can effectively limit the voltage stress of the main power switch $S_{m 1}$. Therefore, the power MOSFET with lower voltage rating and lower on-resistance can be selected to reduce conduction loss. Table 3 shows the total harmonic distortion (THD) and odd-order harmonics of the output voltage $v_{0}$ when the inverter is operated at $48 \mathrm{~V}$ and $72 \mathrm{~V}$ input voltages. The results meet the requirements of electrical standards and verify the correctness of the theoretical analysis again. Figure 12 shows the measured efficiency curve of the active-clamp forward inverter. The highest efficiency is $90.2 \%$ at $48 \mathrm{~V}$ input and $91.5 \%$ at $72 \mathrm{~V}$ input, respectively.

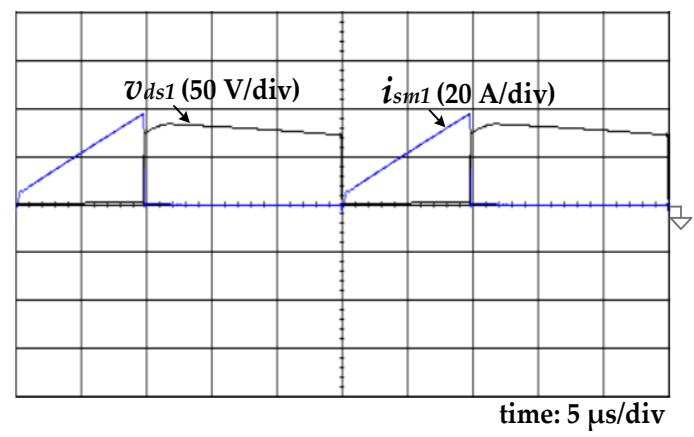

(a)

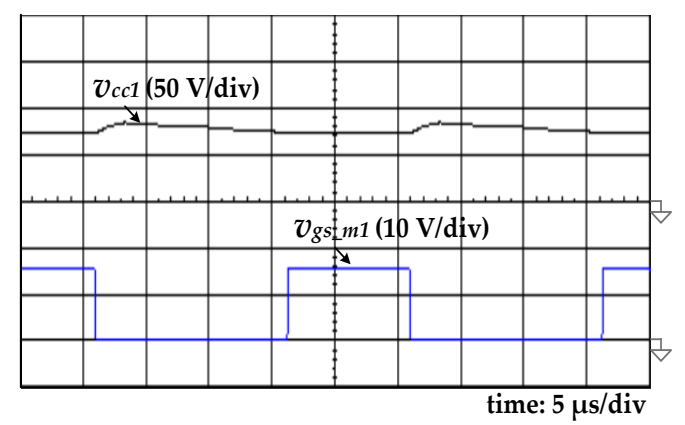

(c)

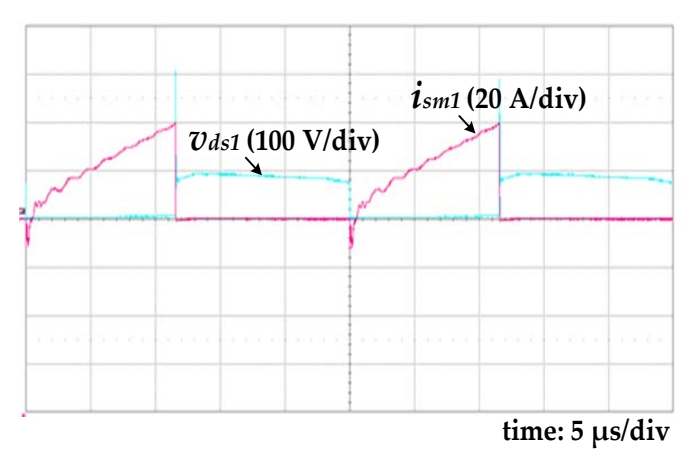

(b)

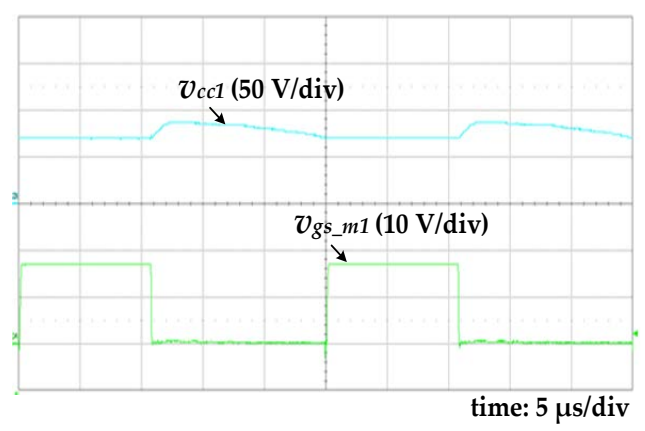

(d)

Figure 11. (a) Simulation waveforms of $v_{d s 1}$ and $i_{s m 1}$, (b) measured waveforms of $v_{d s 1}$ and $i_{s m 1}$, (c) simulation waveforms of $v_{c c 1}$ and $v_{G S \_m 1}$, and (d) measured waveforms of $v_{c c 1}$ and $v_{G S \_m 1}$, when the inverter is operated at the full load of $400 \mathrm{~W}$.

Table 3. Measured T.H.D. and odd-order harmonics of the output voltage.

\begin{tabular}{ccc}
\hline Harmonics & $\mathbf{4 8} \mathbf{~ V}$ & $\mathbf{7 2 ~ V}$ \\
\hline T.H.D. & $2.59 \%$ & $1.47 \%$ \\
3rd Harmonic & $2.42 \%$ & $1.32 \%$ \\
5th Harmonic & $0.83 \%$ & $0.48 \%$ \\
7th Harmonic & $0.32 \%$ & $0.29 \%$ \\
9th Harmonic & $0.18 \%$ & $0.25 \%$ \\
11th Harmonic & $0.15 \%$ & $0.18 \%$ \\
\hline
\end{tabular}




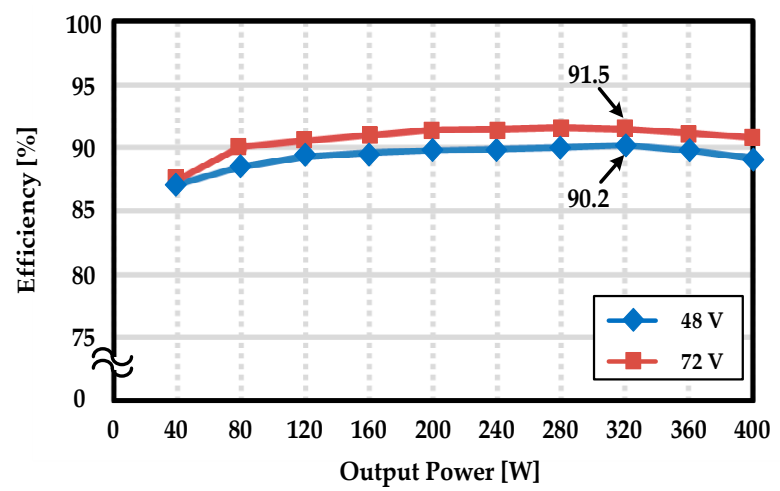

Figure 12. Measured efficiency curve of the active-clamp forward inverter.

Furthermore, Figure 13 shows the measured waveforms of the load current $i_{L}$, the inverter output current $i_{\mathrm{o}}$, the utility-line current $i_{S}$ and the utility-line voltage $v_{s}$, under the operation of grid-connection mode. In this case, the inverter output current $i_{\mathrm{o}}$ is controlled to follow the frequency and the phase of the utility-line voltage $v_{s}$. In this way, the power of the PV panel can be delivered to the load and the utility-line by the proposed active-clamp forward inverter. It can be clearly seen from Figure 13 that the output current is close to an ideal sine wave and in phase with the utility-line voltage. At this condition, the inverter outputs about $200 \mathrm{~W}$ of power, and utility-line provides approximately $200 \mathrm{~W}$ of power to meet the total power requirement of the load. It can prove the feasibility of grid-connection of the proposed inverter. In addition, the power factor, the THD and odd-order harmonics of the output current are measured and recorded in Table 4. Either the THD or each harmonic can meet the specification requirements, and the power factor reaches 0.994 . This further confirms the feasibility of the circuit structure and control strategy mentioned in this paper.

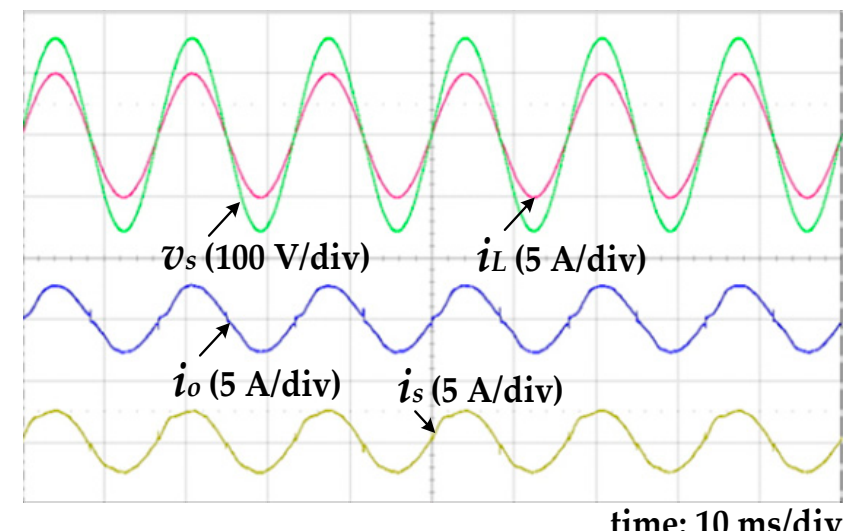

Figure 13. Measured waveforms of the load current $i_{L}$, the inverter output current $i_{\mathrm{O}}$, utility-line current $i_{s}$ and utility-line voltage vs. during grid-connection operation.

Table 4. Measured power factor, T.H.D. and odd-order harmonics of the output current during grid-connection mode.

\begin{tabular}{cc}
\hline \multicolumn{2}{c}{ Power Factor $\mathbf{0 . 9 9 4}$} \\
\hline T.H.D. & $2.23 \%$ \\
3rd Harmonic & $1.92 \%$ \\
5th Harmonic & $0.83 \%$ \\
7th Harmonic & $0.65 \%$ \\
9th Harmonic & $0.34 \%$ \\
11th Harmonic & $0.21 \%$ \\
\hline
\end{tabular}


Many pseudo-dc-link inverters based on forward converters are proposed to improve conversion efficiency and to achieve electrical isolation [20,21]. In order to compare the difference between them and the proposed forward inverter in this paper, a brief discussion is presented as follows according to (1) the reset circuit for residual magnetic flux, (2) the conversion efficiency, (3) the characteristic of switch, and (4) the circuit complexity.

(1) Reset circuit for residual magnetic flux The forward inverter in Reference [20] needs a third winding in series with a diode to reset the residual magnetic flux. Therefore, the maximum duty ratio is limited, resulting in a reduction of boosting capacity. The dual-switch forward inverter in Reference [21] adds an additional power switch and a diode to reset the residual magnetic flux. Since the input current goes through these devices, the volume and cost are greatly increased. In the proposed active-clamp forward inverter, an auxiliary switch and a clamp capacitor are used to reset the residual magnetic flux through the resonance of the clamp capacitor and the magnetizing inductor, which can avoid the problems mentioned above.

(2) Conversion efficiency According to the efficiency curve shown in Figure 12, the efficiency of the active-clamp forward inverter is up to $90.2 \%$ at $48 \mathrm{~V}$ input and $400 \mathrm{~W}$ output power. The measured efficiency of the forward inverter in Reference [20] is $89.5 \%$ at $45 \mathrm{~V}$ input and $110 \mathrm{~W}$. Besides, the measured efficiency of the dual-switch forward inverter in Reference [21] is only $82 \%$ at full load. Therefore, it can be concluded that the proposed inverter has better conversion efficiency than other forward inverters.

(3) Characteristic of switch In the proposed active-clamp forward inverter, both of the main switch and the auxiliary switch have the characteristic of ZVS turn-on. In addition to reducing switching losses, switching noise can also be reduced to avoid electromagnetic interference (EMI) problems. For the forward inverters proposed in References [20,21], the power switches are hard switching, which may increase switching loss and cause serious EMI issues.

(4) Circuit complexity In order to reduce the core size of the transformer, multiple converters with interleaved parallel connections are used in the forward inverter in Reference [20]. Although the efficiency is improved slightly, the circuit complexity and cost are increased significantly. Besides, two dual-switch forward converters are parallel connected in the inverter of Reference [21], and each secondary side of the transformer is center tap, resulting in high circuit complexity. The proposed inverter uses only a single active-clamp forward converter and does not need to add a third winding, so its circuit architecture is much simpler than other forward inverters.

\section{Conclusions}

A single-phase active-clamp forward inverter has been successfully developed and implemented in this paper. The active-clamp forward converter is controlled by SPWM to generate a rectified sine wave, and the full-bridge unfolding circuit with line-frequency switching is used to switch output polarity. This is because only one main switch and one auxiliary switch perform high-frequency switching, and both of them have ZVS turn-on characteristics, which can effectively reduce switching losses and improve efficiency. An auxiliary switch and a clamp capacitor are used to reset the residual magnetic flux of the transformer, so it can recover the energy of the magnetizing inductor to the input, effectively improving the conversion efficiency. The proposed inverter has a transformer so that it can meet the safety requirements of electrical isolation, and has voltage boost capacity suitable for PV power systems. A DSP chip is used instead of a large number of analog components to implement a compact and programmable control circuit. The experimental results have really verified the feasibility of the proposed active-clamp forward inverter. This inverter can be applied to the PV grid-connection power system, which helps to promote the development of renewable energy.

Author Contributions: C.-H.C. and C.-A.C. conceived and designed the circuit; H.-L.C. performed circuit simulations; Y.-T.W. carried out the prototype of the proposed inverter, and measured as well as analyzed experimental results with the guidance from C.-H.C.; C.-A.C. revised the manuscript for submission. All authors have read and agreed to the published version of the manuscript. 
Funding: The authors would like to convey their appreciation for grant support from the Ministry of Science and Technology (MOST) of Taiwan under its grant with reference number MOST 106-2221-E-214-032.

Conflicts of Interest: The authors declare no conflict of interest.

\section{References}

1. Kerekes, T.; Teodorescu, R.; Rodriguez, P.; Vazquez, G.; Aldabas, E. A new high-efficiency single-phase transformerless PV inverter topology. IEEE Trans. Ind. Electron. 2011, 58, 184-191. [CrossRef]

2. Guan, X.; Xu, Z.; Jia, Q.S. Energy-efficient buildings facilitated by microgrid. IEEE Trans. Smart Grid 2010, 1, 243-252. [CrossRef]

3. Chang, C.H.; Chang, E.C.; Cheng, H.L. A high-efficiency solar array simulator implemented by an LLC resonant DC-DC converter. IEEE Trans. Power Electron. 2013, 28, 3039-3046. [CrossRef]

4. Saridakis, S.; Koutroulis, E.; Blaabjerg, F. Optimization of SiC-based H5 and conergy-NPC transformerless PV inverters. IEEE Emerg. Sel. Top. Power Electron. 2015, 3, 555-567. [CrossRef]

5. Azary, M.T.; Sabahi, M.; Babaei, E.; Meinagh, F.A.A. Modified single-phase single-stage grid-tied flying inductor inverter with MPPT and suppressed leakage current. IEEE Trans. Ind. Electron. 2018, 65, 221-231. [CrossRef]

6. Cao, D.; Jiang, S.; Yu, X.; Peng, F.Z. Low-cost semi-Z-source inverter for single-phase photovoltaic systems. IEEE Trans. Power Electron. 2011, 26, 3514-3523. [CrossRef]

7. Abramovitz, A.; Zhao, B.; Smedley, K.M. High-gain single-stage boosting inverter for photovoltaic applications. IEEE Trans. Power Electron. 2016, 31, 550-3558. [CrossRef]

8. Zakzouk, N.E.; Abdelsalam, A.K.; Helal, A.A.; Williams, B.W. PV single-phase grid-connected converter: Dc-link voltage sensorless prospective. IEEE J. Emerg. Sel. Topics Power Electron. 2017, 5, 526-546. [CrossRef]

9. Yang, B.; Li, W.; Zhao, Y.; He, X. Design and analysis of a grid-connected photovoltaic power system. IEEE Trans. Power Electron. 2010, 25, 992-1000. [CrossRef]

10. Li, Q.; Wolfs, P. A review of the single phase photovoltaic module integrated converter topologies with three different DC link configurations. IEEE Trans. Power Electron. 2008, 23, 1320-1333.

11. Meneses, D.; Blaabjerg, F.; García, Ó.; Cobos, J.A. Review and comparison of step-up transformerless topologies for Photovoltaic AC-module application. IEEE Trans. Power Electron. 2013, 28, 2649-2663. [CrossRef]

12. Chang, C.H.; Chang, E.C.; Cheng, C.A.; Shen, C.L. A step-up/down inverter implemented with the boost-interleaved buck-boost dc-dc converter. In Proceedings of the 2015 IEEE 2nd International Future Energy Electronics Conference (IFEEC), Taipei, Taiwan, 1-4 November 2015; pp. 1-6.

13. Chang, C.-H.; Cheng, C.-A.; Cheng, H.-L. An interleaved buck-cascaded buck-boost inverter for PV grid-connection applications. In Proceedings of the 2018 International Power Electronics Conference (IPEC-Niigata 2018-ECCE Asia), Niigata, Japan, 20-24 May 2018.

14. Zhao, Z.; Xu, M.; Chen, Q.; Lai, J.-S.; Cho, Y. Derivation, analysis, and implementation of a boost-buck converter-based high-efficiency PV inverter. IEEE Trans. Power Electron. 2012, 27, 1304-1313. [CrossRef]

15. Chang, C.-H.; Cheng, C.-A.; Chang, E.-C.; Cheng, H.-L. Design and implementation of a two-switch buck-boost typed inverter with universal and high-efficiency features. In Proceedings of the 20159 th International Conference on Power Electronics and ECCE Asia (ICPE-ECCE Asia), Seoul, Korea, 1-5 June 2015; pp. 2737-2743.

16. Gao, M.; Chen, M.; Zhang, C.; Qian, Z. Analysis and implementation of an improved flyback inverter for photovoltaic AC module applications. IEEE Trans. Power Electron. 2014, 29, 3428-3444. [CrossRef]

17. Lee, S.-H.; Cha, W.-J.; Kwon, J.-M.; Kwon, B.-H. Control strategy of flyback microinverter with hybrid mode for PV AC modules. IEEE Trans. Ind. Electron. 2016, 63, 995-1002. [CrossRef]

18. Kim, Y.-H.; Jang, J.-W.; Shin, S.-C.; Won, C.-Y. Weighted-efficiency enhancement control for a photovoltaic AC module interleaved flyback inverter using a synchronous rectifier. IEEE Trans. Power Electron. 2014, 29, 6481-6493. [CrossRef]

19. Tamyurek, B.; Kirimer, B. An interleaved high-power flyback inverter for photovoltaic applications. IEEE Trans. Power Electron. 2015, 30, 3228-3241. [CrossRef]

20. Meneses, D.; García, O.; Alou, P.; Oliver, J.A.; Cobos, J.A. Grid-connected forward microinverter with primary-parallel secondary-series transformer. IEEE Trans. Power Electron. 2015, 30, 4819-4830. [CrossRef] 
21. Zhang, L.; Feng, L.; Xing, Y.; Ma, X. A Single-stage forward inverter with high frequency isolation for grid-connected application. In Proceedings of the 2009 35th Annual Conference of IEEE Industrial Electronics, Porto, Portugal, 3-5 November 2009; pp. 4537-4542.

22. Chen, S.J.; Yang, S.P.; Cho, M.F. Analysis and implementation of an interleaved series input parallel output active clamp forward converter. IET Power Electron. 2013, 6, 774-782. [CrossRef]

(c)

(C) 2020 by the authors. Licensee MDPI, Basel, Switzerland. This article is an open access article distributed under the terms and conditions of the Creative Commons Attribution (CC BY) license (http://creativecommons.org/licenses/by/4.0/). 